\title{
Managing Fusarium Head Blight in Winter Barley With Cultivar Resistance and Fungicide
}

\author{
Christina Cowger, ${ }^{1, \dagger}$ Consuelo Arellano, ${ }^{2}$ David Marshall, ${ }^{1}$ and Joshua Fitzgerald ${ }^{3}$ \\ ${ }^{1}$ U.S. Department of Agriculture - Agricultural Research Service, Department of Plant Pathology, North Carolina State Univer- \\ sity, Raleigh, NC 27695 \\ ${ }^{2}$ Department of Statistics, North Carolina State University, Raleigh, NC 27695 \\ ${ }^{3}$ Crop and Soil Environmental Sciences, Virginia Polytechnic Institute and State University, Blacksburg, VA 24061
}

\begin{abstract}
Although there has been research on managing Fusarium head blight (FHB) in spring barley, little has been published on cultivar resistance and optimal fungicide timing for FHB management in winter barley. A 3 -year (2015 to 2017) field experiment was conducted to measure FHB resistance of winter barley varieties, gauge the potential benefit from a fungicide, and help determine the optimal timing for fungicide application. The split-plot experiment took place in a misted, inoculated nursery in Raleigh, North Carolina using main plots of four winter barley cultivars (Atlantic, Endeavor, Nomini, and Thoroughbred). Three fungicide treatments were applied to subplots: prothioconazole + tebuconazole at full spike emergence, the same fungicide 6 days later, or no fungicide. The late applications significantly reduced FHB index in each of 3 years and significantly

prefer one of the fungicide timings over the other. Across the 3 years, DON ranked the cultivars Endeavor $<$ Nomini $=$ Thoroughbred $<$ Atlantic. Combining the moderate resistance of Endeavor with a fungicide application and averaging the two timings resulted in a 75\% DON reduction compared with unsprayed Atlantic. Taken together, our results indicate that barley growers concerned about minimizing DON should both plant moderately resistant varieties and apply fungicide if there is scab risk. During the same period, 16 commercial winter barley cultivars were tested in from three to seven Virginia and North Carolina environments each, and the DON results were compared after standardization across environments. The winter two-row malting barley cultivars Endeavor and Calypso displayed superior and robust DON resistance across environments.
\end{abstract} reduced deoxynivalenol (DON) in harvested grain in 2 of the 3 years. Applications at full spike emergence also yielded significant benefit in 1 of the 3 years for each parameter. Neither disease symptoms nor DON gave reason to
Keywords: cereals and grains, chemical, disease management, field crops, fungi
Fusarium head blight (FHB; or scab) of wheat (Triticum aestivum $\mathrm{L}$ ) and barley (Hordeum vulgare $\mathrm{L}$ ) is a much-studied disease that lowers yield and contaminates grain with mycotoxins, such as deoxynivalenol (DON). In the United States, the disease is mainly caused by Fusarium graminearum Schwabe sensu lato (Sarver et al. 2011), a fungal pathogen with a wide host range.

For wheat, the U.S. Food and Drug Administration has set $1 \mu \mathrm{g} / \mathrm{g}$ as the advisory ceiling for DON in wheat products, such as flour and bran, that are destined for the human food supply (FDA 2010). Practices demonstrated by research to be most effective in managing wheat FHB are planting moderately resistant cultivars, monitoring risk, and applying fungicides when risk is elevated. In the United States, forecasts of FHB risk are available for spring or winter wheat in 35 states at a national FHB Prediction Center (www.wheatscab. psu.edu) supported by the U.S. Wheat \& Barley Scab Initiative. The models, which are accurate about $75 \%$ of the time, are not designed to predict FHB risk in either spring or winter barley.

With growth in the number of breweries across the United States (Reid and Gatrell 2015), interest in producing malting barley has risen in many areas, including the mid-Atlantic states (C. Cowger, D. Marshall, and J. Fitzgerald, unpublished observations). FHB can be a considerable production constraint, because the tolerance

${ }^{\dagger}$ Corresponding author: C. Cowger; Christina.Cowger@ars.usda.gov

Funding: This material is based on work supported by the U.S. Department of Agriculture in a cooperative project with the U.S. Wheat \& Barley Scab Initiative (USWBSI), and we thank the USWBSI for its support.

The author(s) declare no conflict of interest.

Accepted for publication 6 February 2019.

This article is in the public domain and not copyrightable. It may be freely reprinted with customary crediting of the source. The American Phytopathological Society, 2019. by maltsters and brewers for DON in barley is generally $<0.5 \mathrm{ppm}$ (Kottapalli et al. 2006).

The dynamics of FHB development in barley are less well understood than those in wheat. On average, two-row barleys are more FHB resistant than six-row barleys (Choo et al. 2004; Steffenson 2003; Yoshida and Nakajima 2012; Yoshida et al. 2007). Contradictory findings regarding the timing of greatest susceptibility to FHB infection with respect to growth stages of barley heading and flowering may in part be because of differences in physiology among study regions. Experiments in Japan in both greenhouse and field environments indicated there was a difference in the window of susceptibility in cleistogamous versus chasmogamous (closed flowering versus open flowering) barley, with most two-row barleys being cleistogamous and most six-row types being chasmogamous (Yoshida and Nakajima 2012; Yoshida et al. 2007). In the greenhouse, two-row barleys were more susceptible at 10 or even 20 days after anthesis (daa), whereas six-row barleys were equally susceptible at anthesis and 10 daa and produced more DON and nivalenol when infected at anthesis (Yoshida et al. 2007). The authors attributed this difference to the susceptibility of extruded spent anthers in the two-row cultivars. However, these results may not be directly applicable to the United States, because in Japan, barley usually flowers after spikes emerge from the boot, whereas in U.S. and European spring barleys, flowering occurs in the boot at awn tipping, which is Zadoks 49 (Alqudah and Schnurbusch 2017; Steffenson 2003).

The relative efficacy of fungicides for FHB management has been studied much more extensively for wheat than for barley. National multilocation uniform fungicide trials compared tebuconazole, propiconazole, prothioconazole, tebuconazole + prothioconazole (Prosaro; Bayer Crop Science), and metconazole (Caramba; BASF) using 12 years of data on wheat from 14 U.S. states (Paul et al. 2010). The products leading to the highest mean increase in yield and test weight relative to the check were, in order, metconazole (Caramba), prothioconazole (Proline; Bayer Crop Science), and prothioconazole + tebuconazole (Prosaro). Published data on relative 
fungicide efficacy for reducing FHB in barley are scarce. A 1-year field experiment in Minnesota with a susceptible spring barley cultivar found that several fungicides, including benomyl and tebuconazole, significantly reduced DON concentrations relative to the unsprayed control treatment (Jones 2000). Efficacy in reducing DON in barley was found in single-year studies in North Dakota with tebuconazole + prothioconazole (McMullen et al. 2005; Meyer et al. 2006) and Brazil with metconazole (Reynaldo and Machado 2017). In the Czech Republic, a variety of fungicide treatments applied after full spike emergence significantly reduced DON in both grain and malt of a susceptible spring barley across 2 years; metconazole and tebuconazole + triadimefon provided equivalent control, whereas metconazole plus famoxadone + flusilazole provided significantly greater control (Váňová et al. 2004). The Czech researchers found, however, that assays of malt quality, including gushing in beer, ranked the fungicide treatments differently (Havlová et al. 2006). Exceptionally, no significant improvement in DON or yield compared with the check was found in a 2-year experiment in Minnesota comparing tebuconazole, metconazole, and tebuconazole + prothioconazole on a susceptible spring barley cultivar; DON levels were unusually high (means from 17 to $28 \mu \mathrm{g} / \mathrm{g}$ ) (Hollingsworth et al. 2006).

With respect to optimal fungicide timing, uniform fungicide trials in wheat indicate that FHB symptom and DON reductions from application at Feekes stage 10.5.1 (early flowering) and applications up to 6 days later are equally effective (Paul et al. 2018). Whether there is a similar flexibility in optimal timing for barley has remained unclear, and published data are sparse. In Japan, thiophanate-methyl was applied in the field to a two-rowed variety at various timings before, during, and after flowering and spent anther extrusion (SAE; which is Zadoks growth stage $\sim 73$ or early milk); there was greater FHB reduction from application around the beginning of SAE than earlier or later (Yoshida and Nakajima 2012). In another Japanese field experiment, metconazole at midflowering was more effective at reducing FHB and DON than applications at milk and later stages (Tateishi et al. 2014). Again, the Japanese results may not be applicable to U.S. barley because of differences in flowering phenology as described above. Previously cited experiments with spring barley in Minnesota and North Dakota tested only the Feekes 10.5 (early full head emergence) timing (Hollingsworth et al. 2006; McMullen et al. 2005). A greenhouse study of tebuconazole applications to Fusarium-inoculated spring barley found that, when comparing four growth stages ranging from Feekes 10.3 (spike half emerged) to Feekes 10.54 (kernel watery ripe), the latter timing was the least effective against FHB (Jordahl et al. 2002), but data for comparisons of symptoms and DON among earlier timings were not given in that report or a subsequent report on a greenhouse study with Prosaro (McMullen et al. 2007). Significant differences in DON were not found between Feekes 10.3 10.5, and $10.5+5$ days when Prosaro was applied in a spring barley field experiment in North Dakota (Halley et al. 2009). Thus, it is difficult to draw conclusions from the literature about the optimal timing of fungicide applications to reduce FHB and DON in U.S. barley cultivars.

Although ratings of wheat cultivar resistance to FHB are broadly available in North America, published data on FHB resistance in barley cultivars, especially winter barleys, are less readily available. Problems in field screening have included low disease intensity (Choo et al. 2004) and cultivar rankings that varied greatly among environments (Khatibi et al. 2012). In addition, a methodology is needed to take into account the often large differences among field environments in the range of FHB and DON values to make valid inferences when combining the data across environments.

This integrated management experiment was undertaken to fill gaps in the available information about management of FHB in winter barley, particularly the optimal timing of fungicide application. Because a limited number of cultivars could be used in a misted nursery, we also analyzed DON data from a larger set of winter barley cultivars, some of which are being used in breeding, that were screened for FHB resistance in Virginia and North Carolina during the same period. The results of that analysis are presented here as well.

\section{Materials and Methods}

Integrated management experiment. Experimental design. The experiment was conducted at the Lake Wheeler Road Field Laboratory of North Carolina State University near Raleigh, North Carolina. The four-row plots were $1.2 \mathrm{~m}$ long and $1.5 \mathrm{~m}$ wide, and they were separated by same-sized buffer plots within a planting pass and buffer passes between treatment passes to minimize interplot interference. Planting was performed with a Wintersteiger headrow planter on 22 October 2014, 20 October 2015, and 21 October 2016.

The experiment had a split-plot design with four randomized complete replicate blocks. Main plots were of three commonly planted six-row winter barley cultivars (Atlantic, Nomini, and Thoroughbred) and one two-row winter cultivar (Endeavor). Thoroughbred and Endeavor have acceptable malting quality (AMBA 2018). Three fungicide treatments were applied to subplots: (1) T1 = tebuconazole + prothioconazole (Prosaro) at early full spike emergence (Zadoks 59), (2) T2 = Prosaro 6 days after Zadoks 59, or (3) UNTR = untreated (no fungicide). The treatments were applied to all four replicate plots of each cultivar on the basis of its specific maturity, such that, for example, the T1 treatment was applied on different dates to each cultivar.

Inoculation and misting. Inoculation was provided by means of Fusarium-infected maize kernels. Each year, spores of several $F$. graminearum isolates collected from field-grown wheat spikes in North Carolina were produced as an isolate mixture in Mung tea as described in Cowger and Arellano (2013). Maize was autoclaved on 2 successive days in sterilizable airflow spawn bags (Fungi Perfecti), each containing $1.2 \mathrm{~kg}$ of maize kernels. The bags were opened, and the Fusarium spores were applied to the maize. The bags were resealed, shaken thoroughly, and incubated for 2 weeks, turning and shaking to mix kernels every 2 to 3 days. The bags were then emptied, and the Fusarium-colonized kernels were air dried for 3 weeks on a tarp.

Inoculum was applied three times at 1-week intervals in each year at the rate of $17 \mathrm{~g}$ of Fusarium-infected maize kernels sprinkled in each plot on each occasion in the first 2 years. The rate was increased to $33 \mathrm{~g}$ per plot per application in the final year with the goal of increasing FHB severity. In 2015, the inoculation dates were 6 April ( 8 days before the earliest T1), 13 April, and 20 April (10 days before the latest T2). In 2016, the inoculation dates were 17 March (17 days before the earliest T1), 24 March, and 31 March (22 days before the latest T2). In 2017, the inoculation dates were 7 March, 18 March, and 25 March.

Mist irrigation was applied at a frequency of 2 or $2.5 \mathrm{~min}$ (depending on weather) on and $17 \mathrm{~min}$ off for $3 \mathrm{~h}$ in the morning and $3 \mathrm{~h}$ in the afternoon each day starting when maize inoculum was first applied and continuing until 8 to 14 days after the latest T2.

Fungicide applications. Applications were made with a Solo 435 backpack sprayer using a wand with three XR Teejet flat-fan 8002 VS nozzles mounted $47.6 \mathrm{~cm}$ apart such that the spray angle was $30^{\circ}$ down from horizontal. With a pressure of $30 \mathrm{psi}$, plots were sprayed first in one direction and then in the opposite direction to provide coverage to spikes from both directions. A half rate of Prosaro was applied in each direction such that the total rate of application was 0.585 liters/ha ( 8 ounces per acre), the higher rate labeled for Prosaro to manage FHB in the United States, in a volume of water equivalent to 121.6 liters/ha (13 gallons per acre).

Disease assessment. Three to four weeks after the T1 spray treatments and shortly before symptoms became indistinguishable, disease severity was assessed as the mean of three samples per plot, with each sample consisting of 10 blindly chosen spikes that were individually scored. Severity was scored for each spike as the percentage of symptomatic (blighted) spikelets. Index was calculated as mean disease severity across the 30 sampled spikes in a plot, including spikes with no symptoms.

Grain assays. Plots were hand harvested, and spikes were threshed to retain all kernels. The grain was debearded, and test weight was 
measured with a grain analysis computer (Dickey-John model 2100). In 2016 only, the percentage of kernels infected by the genus Fusarium (percentage infected kernels [PIKs]) was assessed by plating 100 randomly chosen kernels per plot on quarter-strength potato dextrose agar after surface sterilizing the kernels for 2 min in 5\% bleach. Plates were incubated for 7 days at room temperature, and Fusarium infection was determined by colony morphology.

Multienvironment data on 16 cultivars. During the same period from 2015 to 2017,16 commercial winter barley cultivars were each tested in from three to seven environments (location-years) in Mount Holly, Virginia, and Mills River and Raleigh, North Carolina. Each of the 16 cultivars was tested in at least three of seven environments along with other experimental lines and commercial cultivars for which data were not used in this analysis, because they were tested in fewer than three environments.

All of the data were collected in misted, corn spawn-inoculated FHB nurseries except the Mills River data, where the FHB epidemic was natural. The cultivars were grown in small plots, each consisting of two adjacent 1.2-m rows. There were two replicate plots of each cultivar at each location. The Raleigh plots were inoculated as described for the integrated management experiment above, and the Virginia plots were inoculated at boot stage and irrigated with overhead mist until $\sim 1$ week after heading. Grain was hand harvested and threshed.

DON testing. For the integrated management study, $100 \mathrm{~g}$ was subsampled from the yield of each plot and ground to the consistency of coarse flour. The samples were analyzed for DON concentration at the University of Minnesota. For the multienvironment study, the Virginia samples and the Mills River, North Carolina samples were analyzed at the Virginia Polytechnic Institute and State University, whereas the Raleigh, North Carolina samples were analyzed at the University of Minnesota. Both laboratories use gas chromatographymass spectrometry (GC-MS) with the methodology described in Fuentes et al. (2005) and are among four mycotoxin laboratories funded by the U.S. Wheat \& Barley Scab Initiative that calibrate their assays monthly with each other.

Statistical analysis. Integrated management study. Cultivar, fungicide timing, and year were considered fixed variables, and replicate was a random variable. Data were analyzed using SAS MIXED and GLIMMIX procedures, and the Tukey-Kramer test for multiple pairwise predicted mean comparisons was applied. Models using untransformed data for index, DON, test weight, and PIK were compared with those after log and square root transformation of the data, and the model with the best residual distribution and goodness of fit was selected.

The percentage of DON reduction was calculated for each combination of cultivar and fungicide treatment in relation to the unsprayed treatment of Atlantic, the cultivar with the highest DON. The percentage control was found for each observation with respect to untreated Atlantic. Using square root-transformed DON values, PROC GLIMMIX estimated mean percentage control, with cultivar, fungicide treatment, and year as independent variables and replicate(year) and replicate $\times$ variety(year) as random variables. The mean percentage DON reduction was then calculated on the original untransformed scale as $100 \times(1 \%$ control $)$, and lower and upper bounds of the confidence interval were calculated.

Multienvironment DON data on 16 cultivars. Because the range of DON values varied among testing environments, with some having more severe FHB epidemics than others, DON data were rank transformed within each environment using PROC RANK in SAS (SAS Institute) and applying the normal quantile transformation (Ritter and Amin 2014) following a Blom approximation. After ordering observations $y_{i j}$ from lowest to highest DON within each environment, the empirical percentile $p_{i j}$ was calculated by

$$
p_{i j}=\left(\left(r_{i j}+3 / 8\right)\right) /\left(\left(n_{i}+1 / 4\right)\right)
$$

where $r_{i j}$ is the rank (order) of the $j_{t h}$ DON observation in the $i_{t h}$ environment and $n_{i}$ is the number of nonmissing observations in the $i_{t h}$ environment. The normal quantile associated with $p_{i j}$ was found using the inverse function for the standard normal cumulative distribution function. The quantile can be interpreted as the number of standard deviations from the (environment) mean assuming that DON distribution follows a normal distribution, and the effect is to make the data more symmetric.

A one-way model was fitted for normal quantile DON scores, with cultivar as the experimental factor and environments as repetitions, using PROC GLIMMIX with the Satterthwaite criterion owing to the unequal number of observations per cultivar. The level of significance was 0.05 . Least squares (predicted) means for normal quantile DON scores were estimated, and grouping of cultivars into homogeneous groups was determined by the Tukey-Kramer test.

\section{Results}

Environmental effects on maturity. In the integrated management experiment, relative cultivar maturity varied by year, with a 10- to 13-day range each year. Variability in the order of maturation of the cultivars was probably owing to the effects of cold temperatures as they interacted with different growth stages of the four genotypes. In 2015, Nomini was the earliest maturing, and Endeavor was the latest ( $T 1=14$ and 24 April, respectively). In 2016, Endeavor was the earliest, and Thoroughbred was the latest $(\mathrm{T} 1=3$ and 16 April, respectively). In 2017, Atlantic was the earliest, and Thoroughbred was the latest $(\mathrm{T} 1=29$ March and 8 April, respectively).

Some unevenness of maturity was observed in many plots in all 3 years, and it was generally attributable to the effects of cold in delaying development of some plants in comparison with others, even within a plot. The most severe freeze damage was in 2017 , when there were five successive nights of a hard freeze (low temperatures of -5 to $-1^{\circ} \mathrm{C}$ ) $\sim 2$ weeks before full spike emergence in the two earliest cultivars, Atlantic and Nomini. In 2017, Endeavor also exhibited significant winter kill.

Epidemic intensity. Overall, FHB intensity was lower in 2016 than in 2015 or 2017 (Tables 1, 2, and 3). Index varied by cultivar and fungicide timing, but there were significant interactions of the independent variables (Tables 1 and 2). The overall DON level was higher in 2015 than in 2016, with 2017 not different from either

Table 1. Analysis of variance of 3-year misted, inoculated field experiment in Raleigh, North Carolina on cultivar resistance and fungicide timing to manage Fusarium head blight in winter barley ${ }^{\mathrm{y}}$

\begin{tabular}{|c|c|c|c|c|c|c|c|}
\hline \multirow[b]{2}{*}{ Factor $^{\mathbf{z}}$} & \multirow[b]{2}{*}{ Number DF } & \multicolumn{2}{|c|}{ Index } & \multicolumn{2}{|c|}{ DON } & \multicolumn{2}{|c|}{ Test weight } \\
\hline & & $F$ value & $P$ value & $F$ value & $P$ value & $F$ value & $P$ value \\
\hline Cultivar & 3 & 14.13 & $<0.0001$ & 5.19 & 0.0061 & 70.84 & $<0.0001$ \\
\hline Fungicide treatment & 2 & 23.37 & $<0.0001$ & 5.71 & 0.0050 & 5.97 & 0.0041 \\
\hline Cultivar $\times$ fungicide treatment & 6 & 2.75 & 0.0193 & 0.59 & 0.7367 & 1.79 & 0.1148 \\
\hline Year & 2 & 30.20 & $<0.0001$ & 5.11 & 0.0341 & 48.99 & $<0.0001$ \\
\hline Year $\times$ cultivar & 6 & 4.99 & $<0.0010$ & 2.10 & 0.0876 & 13.60 & $<0.0001$ \\
\hline Year $\times$ fungicide treatment & 4 & 3.81 & 0.0076 & 3.05 & 0.0226 & 1.85 & 0.1291 \\
\hline Year $\times$ cultivar $\times$ fungicide treatment & 12 & 2.19 & 0.0221 & 0.92 & 0.5317 & 1.22 & 0.2876 \\
\hline
\end{tabular}

${ }^{\mathrm{y}}$ Index and test weight were log transformed; deoxynivalenol (DON) was square root transformed to provide the best fit of the analysis of variance model. $\mathrm{DF}=$ degrees of freedom.

${ }^{\mathrm{z}}$ The four cultivars were Atlantic, Endeavor, Nomini, and Thoroughbred. The three fungicide treatments were prothioconazole + tebuconazole (Prosaro) at $100 \%$ spikes just fully emerged or 6 days later and an untreated control. 
$(P<0.05)$; the significant year $\times$ fungicide timing interaction was owing to differences in magnitude, not in ranking (Tables 1 and 2). DON varied significantly by cultivar and fungicide timing (Tables 1 and 3 ).

Test weight varied significantly by cultivar and fungicide timing as well as by year, with a significant year $\times$ cultivar interaction (Table 1). Test weight was numerically lowest in 2017 and highest in 2016, although the differences were not significant (Table 4).

Effect of fungicide timing. Index varied by fungicide treatment, but there were significant interactions of treatment with cultivar as well as with year (Table 1 ). The three-way interaction of year $\times$ cultivar $\times$ treatment was significant, and tests of simple effects were used to investigate it. Slicing by year $\times$ cultivar, fungicide treatment significantly affected index for all cultivars in 2015 and 2017 at $P \leq$ 0.056; however, in 2016, the low-FHB year, for three of four cultivars, the effect of fungicide treatment on index was nonsignificant $(P>0.13$; data not shown). Slicing by year $\times$ fungicide treatment, cultivars differed for index in all fungicide treatments at $P<0.056$ in 2015 and 2016, but in 2017, cultivars differed in the sprayed

Table 2. Mean index for a 3-year misted, inoculated field experiment in Raleigh, North Carolina on cultivar resistance and fungicide timing to manage Fusarium head blight in winter barley

\begin{tabular}{lllll}
\hline & \multicolumn{4}{c}{ Index $^{\mathbf{x}}$} \\
\cline { 2 - 5 } Variables & $\mathbf{2 0 1 5}$ & $\mathbf{2 0 1 6}$ & $\mathbf{2 0 1 7}$ & Mean \\
\hline Fungicide timingy & & & & \\
$\quad$ Spikes 100\% emerged (T1) & $25.4 \mathrm{~b}$ & $14.8 \mathrm{ab}$ & $23.5 \mathrm{~b}$ & 21.2 \\
$\quad$ days later (T2) & $18.9 \mathrm{~b}$ & $12.1 \mathrm{~b}$ & $30.1 \mathrm{~b}$ & 20.3 \\
$\quad$ Untreated & $31.3 \mathrm{a}$ & $16.8 \mathrm{a}$ & $43.0 \mathrm{a}$ & 30.3 \\
Cultivar & & & & \\
$\quad$ Endeavor & $11.2 \mathrm{c}$ & $11.3 \mathrm{~b}$ & $24.9 \mathrm{a}$ & 15.8 \\
$\quad$ Thoroughbred & $20.4 \mathrm{~b}$ & $10.9 \mathrm{~b}$ & $36.9 \mathrm{a}$ & 22.7 \\
$\quad$ Nomini & $39.1 \mathrm{a}$ & $14.5 \mathrm{ab}$ & $38.6 \mathrm{a}$ & 30.7 \\
$\quad$ Atlantic & $30.0 \mathrm{ab}$ & $21.5 \mathrm{a}$ & $28.4 \mathrm{a}$ & 26.6 \\
Mean & 25.2 & 14.6 & 32.2 & \\
\hline
\end{tabular}

${ }^{\mathrm{x}}$ Index was mean severity of 30 spikes per plot, including zeroes. Within a variable and column, means followed by the same letter are not significantly different $(P \leq 0.05)$ using the Tukey-Kramer adjustment for multiple comparisons.

${ }^{y}$ Fungicide treatments were prothioconazole + tebuconazole (Prosaro) at $100 \%$ spikes just fully emerged or 6 days later and an untreated control.

${ }^{\mathrm{z}}$ Endeavor was a two-row malting barley cultivar; the others were six row. Thoroughbred was used for malting and feed, whereas Nomini and Atlantic were feed barleys.

Table 3. Mean deoxynivalenol (DON) concentrations from a 3-year misted, inoculated field experiment in Raleigh, North Carolina on cultivar resistance and fungicide timing to manage Fusarium head blight in winter barley ${ }^{\mathrm{x}}$

\begin{tabular}{lllll}
\hline & \multicolumn{4}{c}{ DON $(\boldsymbol{\mu g} / \mathbf{g})$} \\
\cline { 2 - 5 } Variables & $\mathbf{2 0 1 5}$ & $\mathbf{2 0 1 6}$ & $\mathbf{2 0 1 7}$ & Mean \\
\hline Fungicide timing & & & & \\
$\quad$ Spikes 100\% emerged (T1) & $3.63 \mathrm{a}$ & $1.56 \mathrm{ab}$ & $3.27 \mathrm{a}$ & 2.82 \\
$\quad$ days later (T2) & $3.97 \mathrm{a}$ & $1.06 \mathrm{a}$ & $2.25 \mathrm{a}$ & 2.43 \\
$\quad$ Untreated & $5.74 \mathrm{~b}$ & $1.86 \mathrm{~b}$ & $2.58 \mathrm{a}$ & 3.39 \\
Cultivar \\
$\quad$ \\
$\quad$ Endeavor & $2.11 \mathrm{a}$ & $1.05 \mathrm{a}$ & $2.32 \mathrm{ab}$ & $1.83 \mathrm{a}$ \\
$\quad$ Thoroughbred & $2.64 \mathrm{a}$ & $1.38 \mathrm{a}$ & $2.66 \mathrm{ab}$ & $2.22 \mathrm{ab}$ \\
$\quad$ Nomini & $5.48 \mathrm{ab}$ & $1.51 \mathrm{a}$ & $0.96 \mathrm{a}$ & $2.65 \mathrm{ab}$ \\
$\quad$ Atlantic & $7.56 \mathrm{~b}$ & $2.04 \mathrm{a}$ & $4.87 \mathrm{~b}$ & $4.82 \mathrm{~b}$ \\
Mean & 4.45 & 1.49 & 2.70 & \\
\hline
\end{tabular}

${ }^{\mathrm{x}}$ Within a variable and column, means followed by the same letter are not different at $P \leq 0.05$ using the Tukey-Kramer adjustment for multiple comparisons.

${ }^{y}$ Fungicide treatments were prothioconazole + tebuconazole (Prosaro) at $100 \%$ spikes just fully emerged or 6 days later and an untreated control.

${ }^{\mathrm{z}}$ Endeavor was a two-row malting barley cultivar; the others were six row. Thoroughbred was used for malting and feed, whereas Nomini and Atlantic were feed barleys. treatments at $P=0.06$ to 0.07 and the untreated control at $P=0.66$ (data not shown).

Both fungicide timings resulted in a lower index than the untreated control except in 2016, when the difference between $\mathrm{T} 1$ and the control was not significant (Table 2). The three fungicide treatments had the same rank order for index in 2015 and 2016, but in 2017, the two fungicide timings switched ranks. However, in all 3 years over all varieties, there was no significant difference between the two fungicide timings. The overall mean index value for 2016 was lower than those for 2015 and 2017, but the trend was not significant because of interaction.

Across cultivars, there was also no significant difference in DON concentrations between the two fungicide timings in any of the 3 years (Table 3) $(P \geq 0.10)$. Means across years were not separated owing to the significant year $\times$ fungicide treatment interaction. T1 was significantly lower in DON than the unsprayed control in $2015(P=0.005)$ but was not in either of the other 2 years $(P \geq 0.28)$, whereas T2 had significantly lower DON than the unsprayed control in 2015 and $2016(P \leq 0.047)$ but not in $2017(P=0.84)$. Compared with the untreated control, the percentage reduction in DON was $34 \%$ in 2015 averaging the two fungicide timings (31 and 37\%), and 43\% in 2016 when comparing $\mathrm{T} 2$ with the control (Table 3 ).

Across cultivars and years, T2 resulted in a higher test weight than the untreated control treatment $(P=0.003)$, whereas $\mathrm{T} 1 \mathrm{did}$ not $(P=$ 0.17 ) (Table 4). T1 and T2 were not significantly different with regard to test weight $(P=0.25)$. There were no significant differences in test weight in $2015(P \geq 0.44)$ or $2016(P \geq 0.07)$, but T2 produced a higher test weight than the untreated control in $2017(P=$ 0.002), whereas T1 did not $(P=0.12)$.

In 2016, the year for which PIK data were available, fungicide treatment did not have a significant effect on PIK $(P=0.098$; data not otherwise shown).

Effect of cultivar resistance. Averaging across fungicide treatments, Endeavor had the numerically lowest index value in 2 of 3 years and averaged across the years, although the differences were not statistically significant (Table 2). The other three cultivars changed ranks for index during the 3 years. Across years and fungicide timings, Endeavor was lower in DON concentration than Atlantic $(P=0.0043)$, but it was not significantly lower than Thoroughbred $(P=0.75)$ or Nomini $(P=0.66)$ (Table 3$)$. Atlantic was nearly significantly higher in DON than Thoroughbred and Nomini $(P=$ 0.06 in both cases).

Averaged across fungicide timings, test weight differed significantly among cultivars in each year (Table 4). Thoroughbred had the highest test weight in 2015, whereas Atlantic had the highest test weight in 2017. Nomini had the lowest test weight in 2015 and 2016. In 2016, the year for which PIK data were available, cultivar did not have a significant effect on PIK ( $P=0.11$; data not otherwise shown).

Percentage control from management. Relative to the unsprayed treatment of the susceptible cultivar Atlantic, the estimated

Table 4. Mean test weight from a 3-year misted, inoculated field experiment in Raleigh, North Carolina on cultivar resistance and fungicide timing to manage Fusarium head blight in winter barley ${ }^{z}$

\begin{tabular}{lcccc}
\hline & \multicolumn{4}{c}{ Test weight $\left(\mathbf{k g ~ m}^{-\mathbf{3}}\right)$} \\
\cline { 2 - 5 } Variables & $\mathbf{2 0 1 5}$ & $\mathbf{2 0 1 6}$ & $\mathbf{2 0 1 7}$ & Mean \\
\hline Fungicide timing & & & & \\
$\quad$ Spikes 100\% emerged (T1) & $605.3 \mathrm{a}$ & $623.3 \mathrm{a}$ & $571.2 \mathrm{ab}$ & $599.7 \mathrm{ab}$ \\
$\quad$ 6 days later (T2) & $611.8 \mathrm{a}$ & $623.7 \mathrm{a}$ & $579.9 \mathrm{a}$ & $604.9 \mathrm{a}$ \\
$\quad$ Untreated & $609.4 \mathrm{a}$ & $609.9 \mathrm{a}$ & $560.0 \mathrm{~b}$ & $593.3 \mathrm{~b}$ \\
Cultivar & & & & \\
$\quad$ Endeavor & $629.3 \mathrm{~b}$ & $647.4 \mathrm{a}$ & $584.3 \mathrm{a}$ & 620.3 \\
$\quad$ Thoroughbred & $669.2 \mathrm{a}$ & $629.3 \mathrm{a}$ & $574.0 \mathrm{ab}$ & 624.2 \\
$\quad$ Nomini & $611.3 \mathrm{~b}$ & $628.1 \mathrm{a}$ & $568.9 \mathrm{ab}$ & 602.3 \\
$\quad$ Atlantic & $526.4 \mathrm{c}$ & $572.7 \mathrm{~b}$ & $554.7 \mathrm{ab}$ & 550.8 \\
Mean & 608.8 & 619.1 & 570.1 & \\
\hline
\end{tabular}

${ }^{\mathrm{z}}$ Within a variable and column, means followed by the same letter are not different at $P \leq 0.05$ using the Tukey-Kramer adjustment for multiple comparisons. 
percentage DON reduction provided by the moderately resistant cultivar Endeavor was $70 \%$ (Fig. 1). The percentage DON reduction from a fungicide application on Atlantic was 35\% averaging the two spray timings together. The combination of Endeavor's moderate resistance and a fungicide, again averaging the two timings, resulted in a 75\% DON reduction compared with unsprayed Atlantic.

An estimate of $18 \%$ was provided by the analysis as a reduction for unsprayed Atlantic, although it was the standard to which the other treatments were compared (Fig. 1). This simply reflected the variation around the overall mean of DON in unsprayed Atlantic across the 3 years. The confidence intervals take that variability among years into account when indicating differences among treatments.

Multienvironment winter barley DON data. Two of 16 cultivars were present in six and seven environments; 11 were present in four or five environments, and the three hulless cultivars were present in only three environments each (Table 5). DON levels in five of seven North Carolina and Virginia environments had fairly similar ranges; the exceptions were Mt. Holly 2015, where the range was quite large

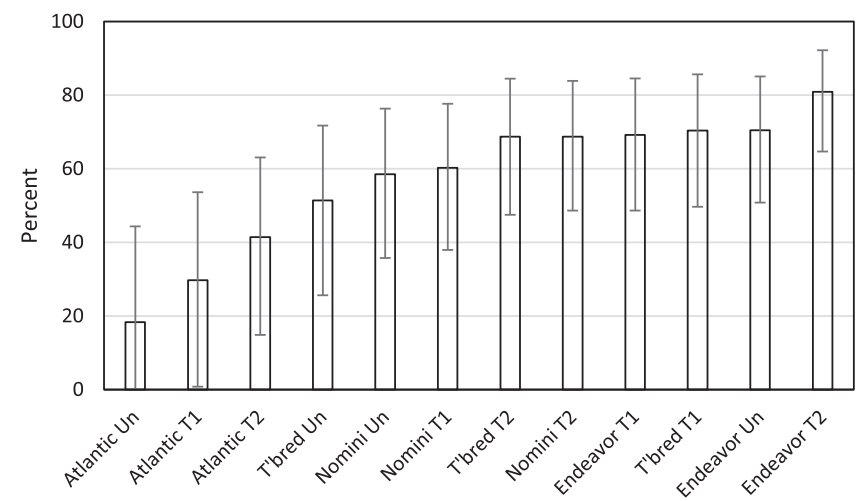

Fig. 1. Percentage reduction in deoxynivalenol provided by combinations of four winter barley cultivars and two fungicide timings relative to the susceptible cultivar Atlantic when unsprayed. Percentage control by unsprayed Atlantic reflects year-to-year variation around the mean (in the text). T1, prothioconazole + tebuconazole applied at $100 \%$ spikes emerged; T2, prothioconazole + tebuconazole applied 6 days later.
(5.3 to $48.8 \mu \mathrm{g} \mathrm{g}^{-1}$ ), and Mills River 2017, the nonirrigated environment where DON ranged only up to $4.5 \mu \mathrm{g} \mathrm{g}^{-1}$.

Across available environments, two two-row malting barley cultivars (Endeavor and Calypso) ranked significantly lower for DON $(P \leq 0.05)$ than the highest-DON entry, the six-row cultivar McGregor. On the whole, the two-row entries tended to have numerically lower DON ranks than the six-row entries; the cultivar Flavia was an exception. The three hulless entries (cultivars Eve, Dan, and Amaze 10) ranked intermediate for DON.

\section{Discussion}

In this study, fungicide applied 6 days after Feekes 10.5 (full spike emergence) of winter barley significantly reduced FHB index in each of 3 years and significantly reduced DON in 2 of 3 years. Applications at Feekes 10.5 also yielded significant benefit in 1 of 3 years for each parameter. The fact that tebuconazole + prothioconazole provided significant FHB and DON reduction agrees with spring barley results from North Dakota (McMullen et al. 2005; Meyer et al. 2006) rather than those from Minnesota (Hollingsworth et al. 2006).

There was no significant difference in FHB and DON reduction when comparing a prothioconazole + tebuconazole (Prosaro) application at full spike emergence with an application 6 days later. To our knowledge, this is the first report of results from a replicated multiyear field test comparing these two fungicide timings in U.S. winter barley. The results suggest that producers have a window of time rather than a specific time point for optimal benefit from prothioconazole + tebuconazole to manage FHB in winter barley. This conclusion is similar to the results of larger uniform trials in wheat. Because these data are from 3 years at the same location, it will be helpful to compare results with tests of these and other timings in multiple winter barley environments. Currently, the only data available for comparison are from fungicide timing studies in field trials of U.S. spring barley and showed no significant difference in DON between Feekes $10.3,10.5$, and $10.5+5$ days as mentioned above, although DON levels in that study were low (Halley et al. 2009).

The reduction in DON owing to the moderate cultivar resistance of Endeavor compared with the susceptible cultivar Atlantic was $70 \%$ averaging across the 3 years. This is a substantial DON reduction, although by itself, it is insufficient in a severe FHB epidemic, because tolerance for DON is practically zero in malting barley. The addition

Table 5. Mean deoxynivalenol (DON) and DON rank of 16 commercial winter barley cultivars grown in at least three of seven Virginia and North Carolina environments from 2015 to 2017

\begin{tabular}{|c|c|c|c|c|c|c|c|c|c|c|c|}
\hline \multirow[b]{2}{*}{ Cultivar } & \multirow[b]{2}{*}{$\begin{array}{l}\text { Accession } \\
\text { number }^{x}\end{array}$} & \multirow[b]{2}{*}{$\begin{array}{c}\text { Type (two } \\
\text { or six row, } \\
\text { hulless) }\end{array}$} & \multicolumn{7}{|c|}{ DON $\left(\mu g g^{-1}\right)^{y}$} & \multirow[b]{2}{*}{$\begin{array}{l}\text { Mean } \\
\text { DON }\end{array}$} & \multirow[b]{2}{*}{$\begin{array}{l}\text { Mean } \\
\text { DON } \\
\text { rank }^{z}\end{array}$} \\
\hline & & & $\begin{array}{l}\text { Mt. Holly, } \\
\text { VA 2015 } \\
(n=34) \\
\end{array}$ & $\begin{array}{c}\text { Raleigh, } \\
\text { NC 2015 } \\
(n=91) \\
\end{array}$ & $\begin{array}{c}\text { Raleigh, } \\
\text { NC 2016 } \\
(n=84) \\
\end{array}$ & $\begin{array}{c}\text { Raleigh, } \\
\text { NC 2017 } \\
(n=89)\end{array}$ & $\begin{array}{c}\text { Mills River, } \\
\text { NC 2017 } \\
(n=14) \\
\end{array}$ & $\begin{array}{c}\text { Mt. Holly, } \\
\text { VA hulled } \\
2017(n=41)\end{array}$ & $\begin{array}{c}\text { Mt. Holly, VA } \\
\text { winter malt } \\
2017(n=30) \\
\end{array}$ & & \\
\hline Endeavor & PI 654824 & 2 & & & 0.3 & 0.4 & 0.8 & & 1.7 & 0.8 & $-1.174 \mathrm{a}$ \\
\hline LCS Calypso & PI 683535 & 2 & & 0.5 & 1.9 & 0.3 & 0.5 & & 1.2 & 0.9 & $-1.105 \mathrm{a}$ \\
\hline SU Mateo & PI 447159 & 2 & & 1.3 & 0.6 & 0.8 & & & 3.2 & 1.5 & $-0.553 \mathrm{ab}$ \\
\hline Violetta & Unknown & 2 & 41.5 & 4.0 & & 0.4 & 0.9 & 1.6 & 2.3 & 8.4 & $-0.330 a b$ \\
\hline Eve & PI 659067 & 6 , hulless & & 5.2 & 0.4 & 1.1 & & & & 2.2 & $-0.145 a b$ \\
\hline Wintmalt & NIC & 2 & & & 1.0 & 0.8 & 0.9 & & 3.0 & 1.4 & $-0.102 a b$ \\
\hline Dan & PI 659066 & 6 , hulless & & 2.3 & 0.8 & 3.4 & & & & 2.2 & $-0.098 \mathrm{ab}$ \\
\hline Charles & PI 637845 & 2 & & 2.7 & 1.1 & 0.7 & 1.6 & & 2.6 & 1.7 & $-0.080 \mathrm{ab}$ \\
\hline Thoroughbred & PI 634933 & 6 & 37.0 & 2.9 & 0.9 & 1.4 & 1.0 & 3.1 & 4.1 & 7.2 & $0.143 \mathrm{ab}$ \\
\hline Atlantic & PI 665041 & 6 & 14.0 & 3.4 & 0.6 & 3.7 & & 5.8 & & 5.5 & $0.183 a b$ \\
\hline Secretariat & PI 673931 & 6 & 33.4 & 4.2 & 0.9 & 1.9 & & 4.8 & & 9.0 & $0.260 \mathrm{ab}$ \\
\hline Flavia & PI 682731 & 2 & & 2.4 & & 3.5 & & 3.4 & 3.2 & 3.1 & $0.263 \mathrm{ab}$ \\
\hline Amaze 10 & PI 675349 & 6 , hulless & & 1.7 & 0.9 & 11.6 & & & & 4.7 & $0.336 \mathrm{ab}$ \\
\hline Wysor & PI 501526 & 6 & 20.8 & 5.7 & 2.2 & 2.9 & & 2.8 & & 6.9 & $0.444 \mathrm{ab}$ \\
\hline Hirondella & NIC & 6 & & & 1.3 & 0.8 & 3.4 & & 6.6 & 3.0 & $0.529 \mathrm{ab}$ \\
\hline McGregor & NIC & 6 & & 5.5 & 5.3 & 2.9 & 4.5 & & 7.9 & 5.2 & $1.267 \mathrm{ab}$ \\
\hline $\begin{array}{l}\text { Environment } \\
\text { DON range }\end{array}$ & & & $5.3-48.8$ & $0.3-19.7$ & $0.1-11.9$ & $0.3-11.6$ & $0.2-4.5$ & $1.6-14.7$ & $0.4-11.3$ & & \\
\hline
\end{tabular}

${ }^{\mathrm{x}}$ Accession number in the U.S. Department of Agriculture ARS National Small Grains Collection. NIC, not in collection.

y The $n$ values are total numbers of cultivars in each test; data for other entries are not shown.

${ }^{\mathrm{z}} \mathrm{DON}$ rank was calculated by adjusting per-environment ranks using the normal quantile distribution owing to uneven numbers of environments by cultivar and varying DON ranges per environment. Values followed by the same letter are not different at $P \leq 0.05$. 
of the fungicide brought the percentage reduction in DON only up to $75 \%$ in Endeavor. Combining the cultivars Nomini and Thoroughbred with fungicide provided DON reductions of 60 to $70 \%$. Although fungicide is helpful, and in a severe epidemic essential, cultivar resistance played the largest role in this experiment. The multienvironment data, which are discussed below, confirmed that Endeavor had robust resistance to DON.

The DON data support ratings of moderately resistant for Endeavor, moderately susceptible for Thoroughbred and Nomini, and susceptible for Atlantic. Nomini had relatively high index values in all 3 years, especially 2015 and 2017. The DON level in Nomini was also relatively high except in 2017 , when it was unexpectedly low, possibly owing to the interaction of cold temperature with flowering and disease development. The two earliest-heading cultivars in 2017 were Atlantic and Nomini, and there were five nights of hard freeze 14 to 17 days before T1 for those two cultivars. In 2017, Nomini and Atlantic had the lowest and highest DON levels, respectively, although Nomini had a high index. It is possible that the freeze episode had a stronger effect on Nomini than on Atlantic.

In general, DON levels were more variable in 2017, and they were not consistently reduced by fungicide applications. This failure of DON reduction is likely owing to the variability in heading induced by cold injury. DON was atypically low in Nomini in 2017, whereas index was relatively high, which could have been because of weather fluctuations and the effects of cold temperatures. Winter barley is less cold tolerant than winter wheat, and its cold hardiness is a function of its ability to harden and deharden during periods of varying temperatures (Rapacz et al. 2008; Rizza et al. 1994). Unevenness in jointing and heading may be caused by cold periods and can confound assays of FHB responses (C. Cowger, unpublished observations).

T1 was selected for this winter barley study because of the North Dakota recommendation that fungicide should be applied to spring barley for FHB control at $100 \%$ spikes emerged. T2 was selected because of research in wheat, cited above, indicating that "late" fungicide applications provided benefits equivalent or nearly equivalent to early-anthesis applications. Our results are, therefore, not directly comparable with those of Yoshida and Nakajima (2012), who found that fungicide applied at the growth stage of SAE provided better FHB control in barley than at earlier or later timings.

The optimal timing for FHB-directed fungicide application in winter barley requires additional study. For one thing, confusion exists in the literature as to the timing of barley anthesis in relation to heading. For example, Geddes et al. (2008) inoculated barley spikes at Zadoks 65 , which they called anthesis, in the greenhouse. However, Alqudah and Schnurbusch (2017) indicate that, in spring barley, anthesis and fertilization occur at awn tipping (Zadoks 49; i.e., when the tips of awns are just visible and the spike is still in the boot), whereas anthesis or fertilization mostly occur after Zadoks 49 in winter barley. Anther extrusion (Zadoks 60 to 69) usually occurs after heading in barley and is much later than anthesis/fertilization.

Even when the timing of anthesis is clarified, however, published research remains scarce on the timing of maximum barley susceptibility to FHB relative to anthesis or heading. A detailed study by Lewandowski et al. (2006) concluded that the genus Fusarium gains access to the interior of barley florets through crevices between the lemma and palea and through the apical floret mouth. The study was conducted with field-grown barley spikes that were spray inoculated with $F$. graminearum macroconidia when $90 \%$ of spikes had emerged, thus confining the infection timing under study to that growth stage. To our knowledge, it is uncertain to what extent infections can also occur earlier and later.

The DON results on the 16 commercial cultivars illustrate the importance and also the pitfalls of multiple environment testing when the trait of greatest interest, DON, is highly variable within and among environments. The wide variability in DON scales and also cultivar DON ranking among environments (e.g., Khatibi et al. 2012 ) is typical of inoculated, irrigated FHB nurseries, and it likely has to do with varying heading dates, weather conduciveness, inoculum potency, and total moisture provided. This variability may be especially typical of barley FHB in comparison with wheat FHB owing to the particular tendency of winter barley to head unevenly (C. Cowger, D. Marshall, and J. Fitzgerald, unpublished observations). By transforming the multiscale DON data to a common scale, we were able to compensate for some of this variability, but the degree to which means could be separated remained modest.

Nevertheless, we did show robust, superior DON resistance for two of the two-row cultivars, Endeavor and Calypso. This signifies that these cultivars should be useful in efforts to breed DONresistant barleys for the malting industry. Furthermore, the mean DON ranking from our 16-cultivar dataset agreed with the relative ranking from the 4-cultivar integrated management experiment of Endeavor $<$ Thoroughbred $\leq$ Atlantic, lending additional credibility to the results.

In conclusion, this research suggests that winter barley producers who apply prothioconazole + tebuconazole can anticipate obtaining the same degree of FHB reduction with applications at $100 \%$ spikes emerged or 6 days later. In other words, producers who are unable to access the field owing to weather at full spike emergence can wait for drier conditions and expect a similar benefit when applying the fungicide several days later. The research suggests that fungicide efficacy for FHB reduction in winter barley is modest but that a combination of moderate resistance and fungicide can reduce scab by a substantial percentage. In addition, there are differences in DON resistance among two- and six-row commercial winter barley cultivars that are used in production or breeding programs. Two commercial barley cultivars, Endeavor and Calypso, showed environmentally robust DON resistance and are thus useful in breeding to minimize DON in malting barley.

\section{Acknowledgments}

We thank the laboratories of Dr. Y. Dong and Dr. D. Schmale for deoxynivalenol analysis and E. T. Cole, M. Hargrove, and S. Walsh for excellent technical support.

\section{Literature Cited}

Alqudah, A. M., and Schnurbusch, T. 2017. Heading date is not flowering time in spring barley. Front. Plant Sci. 8:896.

AMBA. 2018. Recommended Malting Barley Varieties. American Malting Barley Association. http://ambainc.org/content/64/recommended

Choo, T. M., Martin, R. A., Ho, K. M., Shen, Q., Fedak, G., Savard, M., Voldeng, H., Falk, D. E., Etienne, M., and Sparry, E. 2004. Fusarium head blight and deoxynivalenol accumulation of barley in eastern Canada: Cultivar response and correlation analysis. Plant Dis. 88:837-844.

Cowger, C., and Arellano, C. 2013. Fusarium graminearum infection and deoxynivalenol concentrations during development of wheat spikes. Phytopathology 103:460-471.

FDA. 2010. Guidance for Industry and FDA: Advisory Levels for Deoxynivalenol (DON) in Finished Wheat Products for Human Consumption and Grains and Grain By-Products Used for Animal Feed. U.S. Department of Health and Human Services. https://www.fda.gov/ regulatory-information/search-fda-guidance-documents/guidance-industryand-fda-advisory-levels-deoxynivalenol-don-finished-wheat-products-human

Fuentes, R. G., Mickelson, H. R., Busch, R. H., Dill-Macky, R., Evans, C. K., Thompson, W. G., Wiersma, J. V., Xie, W., Dong, Y., and Anderson, J. A. 2005. Resource allocation and cultivar stability in breeding for Fusarium head blight resistance in spring wheat. Crop Sci. 45:1965-1972.

Geddes, J., Eudes, F., Tucker, J. R., Legge, W. G., and Selinger, L. B. 2008 Evaluation of inoculation methods on infection and deoxynivalenol production by Fusarium graminearum on barley. Can. J. Plant Pathol. 30: 66-73.

Halley, S., Van Ee, G., Hofman, V., Horsley, R. D., Neate, S., and Misek, K. 2009. Integrating resistance, best application timing and best fungicide delivery technique for improved efficacy on barley, Langdon, 2008. Pages 50-55 in: Proceedings of the 2009 National Fusarium Head Blight Forum. A. M. Canty, A. Clark, J. Mundell, E. Walton, D. Ellis, and D. Van Sanford, D., eds. U.S. Wheat \& Barley Scab Initiative, East Lansing, MI.

Havlová, P., Lancová, K., Váňová, M., Havel, J., and Hajšlová, J. 2006. The effect of fungicidal treatment on selected quality parameters of barley and malt. J. Agric. Food Chem. 54:1353-1360.

Hollingsworth, C. R., Motteberg, C. D., and Thompson, W. G. 2006. Assessing fungicide efficacies for the management of Fusarium head blight on spring wheat and barley. Plant Health Prog. 7:1.

Jones, R. K. 2000. Assessments of Fusarium head blight of wheat and barley in response to fungicide treatment. Plant Dis. 84:1021-1030.

Jordahl, J., Meyer, S., and McMullen, M. 2002. Multiple infection events and split timing of Folicur fungicide applications for control of FHB in hard red spring wheat, durum wheat, and spring barley. Page 90 in: Proceedings of the 2002 
National Fusarium Head Blight Forum. S. M. Canty, J. Lewis, L. Siler, and R. W. Ward, eds. U.S. Wheat \& Barley Scab Initiative, East Lansing, MI.

Khatibi, P. A., Berger, G., Liu, S., Brooks, W. S., Griffey, C. A., and Schmale,

D. G. 2012. Resistance to Fusarium head blight and deoxynivalenol accumulation in Virginia barley. Plant Dis. 96:279-284.

Kottapalli, B., Wolf-Hall, C. E., and Schwarz, P. 2006. Effect of electron-beam irradiation on the safety and quality of Fusarium-infected malting barley. Int. J. Food Microbiol. 110:224-231.

Lewandowski, S. M., Bushnell, W. R., and Evans, C. K. 2006. Distribution of mycelial colonies and lesions in field-grown barley inoculated with Fusarium graminearum. Phytopathology 96:567-581.

McMullen, M., Jordahl, J. G., and Meyer, S. 2005. Evaluation of Fungicides for Control of Fusarium Head Blight and Net Blotch in Barley, 2005. Fungicide and Nematicide Tests. The American Phytopathological Society, St. Paul, MN.

McMullen, M., Meyer, S., and Jordahl, J. 2007. Effects of fungicide timing on Fusarium head blight and on DON and DON derivatives in three spring grains. Page 101 in: Proceedings of the 2007 National Fusarium Head Blight Forum. S. M. Canty, A. Clark, D. Ellis, and D. Van Sanford, D., eds., University of Kentucky, Lexington, KY.

Meyer, S., Jordahl, J., and McMullen, M. 2006. Uniform fungicide trial results on HRS wheat and barley, Fargo, ND 2006. Page 14 in: Proceedings of the 2006 National Fusarium Head Blight Forum. S. M. Canty, A. Clark, and D. Van Sanford, eds., U.S. Wheat \& Barley Scab Initiative, East Lansing, MI.

Paul, P., McMullen, M., Hershman, D., and Madden, L. 2010. Meta-analysis of the effects of triazole-based fungicides on wheat yield and test weight as influenced by Fusarium head blight intensity. Phytopathology 100:160-171.

Paul, P. A., Bradley, C. A., Madden, L. V., Dalla Lana, F., Bergstrom, G. C., DillMacky, R., Wise, K., Esker, P. D., McMulllen, M. P., Grybauskas, A., Kirk, W. W., Milus, E., and Ruden, K. 2018. Effects of pre-and post-anthesis applications of demethylation inhibitor fungicides on Fusarium head blight and deoxynivalenol in spring and winter wheat. Plant Dis. 102:2500-2510.

Rapacz, M., Tyrka, M., Kaczmarek, W., Gut, M., Wolanin, B., and Mikulski, W. 2008. Photosynthetic acclimation to cold as a potential physiological marker of winter barley freezing tolerance assessed under variable winter environment. J. Agron. Crop Sci. 194:61-71.

Reid, N., and Gatrell, J. D. 2015. Brewing growth. Econ. Dev. J. 14:5-12.

Reynaldo, É. F., and Machado, T. M. 2017. Performance of spray nozzles to control Fusarium head blight and mycotoxin in the barley crop. Rev. Bras. Eng. Agric. Ambient. 21:209-213.

Ritter, E. K., and Amin, R. 2014. Are Caribbean reef sharks, Carcharhinus perezi, able to perceive human body orientation? Anim. Cogn. 17:745-753.

Rizza, F., Crosatti, C., Stanca, A. M., and Cattivelli, L. 1994. Studies for assessing the influence of hardening on cold tolerance of barley genotypes. Euphytica 75: 131-138.

Sarver, B. A. J., Ward, T. J., Gale, L. R., Broz, K., Corby Kistler, H., Aoki, T. Nicholson, P., Carter, J., and O'Donnell, K. 2011. Novel Fusarium head blight pathogens from Nepal and Louisiana revealed by multilocus genealogical concordance. Fungal Genet. Biol. 48:1096-1107.

Steffenson, B. J. 2003. Fusarium head blight of barley: Impact, epidemics, management, and strategies for identifying and utilizing genetic resistance. Pages 241-295 in: Fusarium Head Blight of Wheat and Barley. K. J. Leonard and W. R. Bushnell, eds. American Phytopathological Society, St. Paul, MN.

Tateishi, H., Miyake, T., Mori, M., Sakuma, Y., and Saishoji, T. 2014. Effect of application timing of metconazole on Fusarium head blight development and mycotoxin contamination in wheat and barley. J. Pestic. Sci. 39:1-6.

Váňová, M., Hajšlová, J., Havlová, P., Matušinsky, P., Lancová, K., and Spitzerová, D. 2004. Effect of spring barley protection on the production of Fusarium spp. mycotoxins in grain and malt using fungicides in field trials. Plant Soil Environ. 50:447-455.

Yoshida, M., Kawada, N., and Nakajima, T. 2007. Effect of infection timing on Fusarium head blight and mycotoxin accumulation in open- and closedflowering barley. Phytopathology 97:1054-1062.

Yoshida, M., and Nakajima, T. 2012. Chemical control of Fusarium head blight and mycotoxin contamination in barley and wheat based on mycotoxin accumulation during grain development. Mycotoxins 62:19-27. 